\title{
Labelling completeness and sodium content of packaged foods in India
}

Claire Johnson $^{1,2, *}$, Sudhir Raj Thout ${ }^{3}$, Sailesh Mohan ${ }^{4}$, Elizabeth Dunford ${ }^{1,5}$, Clare Farrand $^{1,2}$, Jason HY Wu ${ }^{1,2}$, Feng J He ${ }^{6}$, Roopa Shivashankar ${ }^{4}$, Jacqui Webster ${ }^{1,2}$, Anand Krishnan ${ }^{7}$, Vandana Garg ${ }^{4}$, Pallab K Maulik ${ }^{2,8}$, Dorairaj Prabhakaran ${ }^{4,9}$ and Bruce Neal ${ }^{1,2,10,11,12}$

${ }^{1} T$ The George Institute for Global Health, PO Box M20, Missenden Road, NSW 2050, Australia: ${ }^{2}$ The University of Sydney, Sydney, NSW, Australia: ${ }^{3}$ The George Institute for Global Health India, Hyderabad, India: ${ }^{4}$ Public Health Foundation of India, Gurgaon, Haryana, India: ${ }^{5}$ Carolina Population Center, The University of North Carolina, Chapel Hill, NC, USA: 'Wolfson Institute of Preventive Medicine, Barts and The London School of Medicine \& Dentistry, Queen Mary University of London, London, UK: ${ }^{7}$ All India Institute of Medical Sciences, New Delhi, India: ${ }^{8}$ The George Institute for Global Health, University of Oxford, Oxford, UK: ${ }^{9}$ Centre for Chronic Disease Control, Haryana, India: ${ }^{10}$ Charles Perkins Centre, The University of Sydney, Camperdown, NSW, Australia: ${ }^{11}$ Imperial College London, London, UK: ${ }^{12}$ Royal Prince Alfred Hospital, Camperdown, NSW, Australia

Submitted 25 October 2016: Final revision received 19 June 2017: Accepted 27 June 2017: First published online 22 August 2017

\begin{abstract}
Objective: To estimate the proportion of products meeting Indian government labelling regulations and to examine the Na levels in packaged foods sold in India. Design: Nutritional composition data were collected from the labels of all packaged food products sold at Indian supermarkets in between 2012 and 2014. Proportions of products compliant with the Food Safety Standards Authority of India (FSSAI) regulations and labelled with $\mathrm{Na}$ content, and mean $\mathrm{Na}$ levels were calculated. Comparisons were made against 2010 data from Hyderabad and against the UK Department of Health (DoH) 2017 Na targets.

Setting: Eleven large chain retail stores in Delhi and Hyderabad, India.

Subjects: Packaged food products ( $n$ 5686) categorised into fourteen food groups, thirty-three food categories and ninety sub-categories.

Results: More packaged food products ( $43 v .34 \% ; P<0 \cdot 001)$ were compliant with FSSAI regulations but less $(32 v .38 \% ; P<0.001)$ reported $\mathrm{Na}$ values compared with 2010. Food groups with the highest $\mathrm{Na}$ content were sauces and spreads $(2217 \mathrm{mg} / 100 \mathrm{~g})$ and convenience foods $(1344 \mathrm{mg} / 100 \mathrm{~g})$. Mean Na content in 2014 was higher in four food groups compared with 2010 and lower in none $(P<0.05)$. Only $27 \%$ of foods in sub-categories for which there are UK DoH benchmarks had Na levels below the targets.

Conclusions: Compliance with nutrient labelling in India is improving but remains low. Many packaged food products have high levels of $\mathrm{Na}$ and there is no evidence that Indian packaged foods are becoming less salty.
\end{abstract}

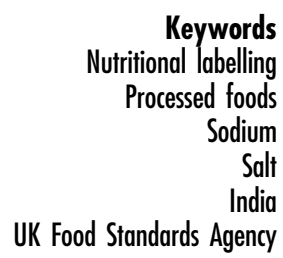

CVD are the leading cause of death in India and are responsible for approximately $2 \cdot 3$ million deaths each year, of which almost a quarter are ascribed to high blood pressure $^{(1,2)}$. There were approximately 118 million individuals with hypertension in 2000 and this number is expected to reach 213 million by $2025^{(3)}$. Excess salt consumption is a leading cause of high blood pressure and has been reported as the seventh leading cause of global mortality, responsible for one in ten cardiovascular deaths worldwide ${ }^{(4,5)}$.

The Indian diet is traditionally characterised by high intakes of fruits, vegetables and unprocessed coarse cereals and pulses ${ }^{(6)}$. However, National Nutrition Surveys done over the past 20 years have shown a change in consumption patterns towards more processed and restaurant foods ${ }^{(7)}$. This shift affects mainly middle- and highincome groups and appears to be driven by changes in the food environment which are making a wider range of processed food products accessible ${ }^{(8)}$. In conjunction with increased average per capita income, these types of products are accessible by a larger proportion of the population with increased risk of exposure to adverse nutrients like saturated fats, sugars and salt ${ }^{(4)}$. 
The known benefits of salt reduction for lowering blood pressure make a strong case for a reduced amount of salt in the Indian food supply. A recent survey of $24 \mathrm{~h}$ urinary $\mathrm{Na}$ excretion among a population of 1395 adults in India reported an average intake of $9.27 \mathrm{~g}$ salt $/ \mathrm{d}^{(9)}$, which, when inflated to account for the minimum likely non-urinary losses of $\mathrm{Na}$, equates to $10 \cdot 20 \mathrm{~g}$ salt/d. This is consistent with a systematic review of salt intake among adult Indians which reported intake as $10.98 \mathrm{~g} / \mathrm{d}^{(10)}$. India has ratified the WHO global monitoring framework for the prevention and control of non-communicable diseases $(2013-2020)^{(11)}$, which includes a target to reduce salt intake by $30 \%$ by 2025 . The design and implementation of an optimal national salt reduction strategy will require knowledge about salt intake levels around the country and the sources of salt in the food supply $^{(12)}$. Packaged foods are likely a large and increasing source of dietary salt for many people in India and information about the salt levels in foods will be vital to the design of a national salt reduction programme. Many other countries have set benchmarks for the labelling of salt on foods and targets for the maximum levels of salt in key packaged food categories ${ }^{(13,14)}$.

In 2011, the Food Safety and Standards Authority of India (FSSAI) introduced new national nutrition labelling regulations that require core information describing the nutritional content of processed foods to include energy (kilocalories), protein, carbohydrate and fat (grams) per $100 \mathrm{~g}$ or $100 \mathrm{ml}$ serving of the product ${ }^{(15)}$. Data for the current survey (2012-2014) were collected after the introduction of these new requirements. A prior survey done in 2010 before the 2011 regulation provided for historical comparisons ${ }^{(16)}$. As such, we estimated: (i) the current proportion of packaged foods in India displaying the nutrition information required by the Indian regulation and how this compared with 2010; (ii) the average levels of $\mathrm{Na}$ in Indian packaged foods and how these compared with 2010; and (iii) the proportion of Indian packaged foods known to meet Na content targets for 2017 set by the UK Department of Health $(\mathrm{DoH})^{(13)}$. Salt is the major source of $\mathrm{Na}$ in the diet $(1 \mathrm{~g} \mathrm{Na}=2.5 \mathrm{~g}$ salt $)$.

\section{Materials and methods}

The present study comprised a systematic survey of packaged foods for sale in urban Hyderabad and New Delhi, India with data collection undertaken over a 27-month period from July 2012 to September 2014.

\section{Retail outlets surveyed}

The stores were purposively selected to ensure that a broad range of foods representative of packaged products for sale in Hyderabad and New Delhi were included. There were eleven stores from which data were collected; seven retail chains (HyperCity supermarket; MORE retail; Food World; Heritage Supermarket; Ratnadeep supermarket; Dilip Supermarket; Nilgiris supermarket) and four smaller local stores (SSK Supermarket, Jubilee Kirana; General Stores, Tilaknagar Kirana; General Store, Maheshwari Kirana; General Store). Permission to collect data was obtained from each store. It was not possible to obtain permission to collect data from five other stores that were similar in size to the retail chain stores, but it is likely that product ranges in those five stores overlapped substantially with those from which data were collected.

\section{Packaged foods included}

All packaged food products that were available for sale in each store during the period of data collection were recorded. Surveys were carried out twice during the 27-month period and all data were combined. During each product survey, data collection staff captured the barcode and photographed the front of the pack, the nutrition label and the ingredients list for every packaged food item on every shelf in every outlet surveyed. This was done using a smartphone application developed by The George Institute for Global Health ${ }^{(17)}$ and according to a protocol devised by an international collaborative project designed to document the nutritional composition of packaged foods globally ${ }^{(18)}$. The images collected by the smartphone application are transmitted to a data management centre in India for processing.

\section{Data extraction}

The data management centre uses a bespoke content management system to view the images and transfer data describing the product into the database. The key variables used for the current analysis were the brand name, product name, manufacturer name, serving size and presence of nutritional information per $100 \mathrm{~g}$ (or per $100 \mathrm{ml}$ for liquids) for energy, protein, carbohydrate, sugar, total fat, $\mathrm{Na}$ and saturated fat. Where data were absent it was recorded as missing. Where nutritional information was provided 'as sold' or 'as prepared' then the former was used to ensure a standardised approach and to facilitate comparison against the UK DoH 2017 Na targets. Different pack sizes of the same product were recorded as separate items in the database but each product was included only once in the primary analyses.

\section{Categorisation of foods}

Foods were categorised using the system developed by the Global Food Monitoring Group ${ }^{(18)}$ into fourteen main food groups: (i) bread and bakery products; (ii) cereal and grain products; (iii) confectionery; (iv) convenience foods; (v) dairy and dairy alternatives; (vi) edible oils and oil emulsions; (vii) fish and fish products; (viii) fruit and vegetables; (ix) meat and meat products; (x) non-alcoholic beverages; (xi) sauces and spreads; (xii) snack foods; (xiii) sugars, honey and related products; and (xiv) special foods. Eight of these main food groups known to contribute significant quantities of salt to the diet were further 
subdivided to provide data about fourteen finer product categories known to be main contributors to salt in the diet and to enable comparison of products against matched categories with UK DoH 2017 Na targets. Alcohol, vitamins and supplements, and products that could not be categorised were excluded from the analyses. The special foods category encompasses baby food and protein supplements including protein bars.

\section{Comparator data from 2010}

Nutritional data per $100 \mathrm{~g}$ (or per $100 \mathrm{ml}$ for liquids) for energy, protein, carbohydrate, sugar, total fat, $\mathrm{Na}$ and saturated fat on products collected in a survey conducted in 2010 in Hyderabad using a similar data collection protocol $^{(16)}$ were used to make comparisons with the current survey in terms of the proportion of packaged foods meeting FFSAI labelling requirements (reporting data about energy, protein, carbohydrate, sugar and total fat), the proportion with $\mathrm{Na}$ labelled, and the mean concentration of $\mathrm{Na}$ in foods with the requisite labelling.

\section{Statistical analysis}

Analyses were variously done for all products combined and specific food categories. There were three main sets of analyses: (i) the proportions of packaged foods in India carrying FSSAI-legislated minimum nutritional information were calculated and compared with data from 2010 using $\chi^{2}$ tests. Separate analyses were done for the proportion of products carrying data about Na content; (ii) the average levels of $\mathrm{Na}$ in packaged foods for which data were available were calculated for 2014 and 2010 along with mean differences and 95\% CI and compared using unpaired $t$ tests. These comparisons were repeated using medians since some data were asymmetrically distributed; and (iii) the proportion of packaged foods known to meet' maximum Na content targets for 2017 set by the UK DoH were calculated for fourteen food sub-categories for which direct comparison could be made. Foods were defined as 'known to meet' the target if the label reported an $\mathrm{Na}$ content that was below the specified target. All analyses were done using the statistical software package Stata version $13.1 ; P$ values less than 0.05 were considered as likely to indicate a finding that had not arisen solely by chance.

\section{Results}

Data were collected for 5789 products and 103 products were subsequently excluded as they were alcohol $(n 6)$, vitamins or supplements ( $n$ 82) or products that could not be categorised ( $n$ 15). This left 5686 products in fourteen food groups upon which the main analyses were based. Packaged fruit and vegetable products, including tinned, frozen, jarred and dried fruit and vegetables, were the food group with the largest number of products comprising $21 \%$ of the total, followed by cereal and cereal products (14\%) and non-alcoholic beverages $(12 \%)$. Fish and fish products had the least number of products, making up $<1 \%(n$ 46) of the total. The data set from 2010 included 4166 products distributed across the same fourteen food groups. In the 2010 data the largest food groups were packaged fruit and vegetable products (19\%), cereal and cereal products (12\%) and bread and bakery products (11\%), and the fewest numbers of items were in fish and fish products (1\%).

\section{Compliance with national labelling regulations}

Forty-three per cent of products ( $n$ 2468) met the FSSAI regulations for labelling and $32 \%$ ( $n$ 1812) were labelled for Na content (Table 1). Across the fourteen food groups there were nine groups for which the proportion meeting FSSAI requirements had increased since 2010 and five for which there was no difference (Table 2). Overall, the proportion meeting FSSAI labelling requirements increased from 34 to $43 \%(P<0 \cdot 001)$ over this period. In terms of Na labelling there were six food groups for which the proportion labelled with $\mathrm{Na}$ decreased significantly, and overall the proportion declined from 38 to $32 \%$ $(P<0 \cdot 001$; Table 3$)$.

\section{Mean sodium content of packaged foods}

Mean $\mathrm{Na}$ values were highest in sauces and spreads $(2217 \mathrm{mg} / 100 \mathrm{~g})$ and particularly in the meal-based sauces sub-category, which had mean $\mathrm{Na}$ content of $3240 \mathrm{mg} / 100 \mathrm{~g}$. The food group with the lowest Na content was sugars, honey and related products $(44 \mathrm{mg} / 100 \mathrm{~g}$ ), and the mean $\mathrm{Na}$ content of confectionery $(98 \mathrm{mg} / 100 \mathrm{~g})$ and non-alcoholic beverages $(119 \mathrm{mg} / 100 \mathrm{~g})$ was also low (Table 3). In addition to varying between food groups, Na content also varied markedly within many food groups and within food sub-categories. For example, within sauces and spreads the $\mathrm{Na}$ content of individual products ranged from 0 to $21218 \mathrm{mg} / 100 \mathrm{~g}$. The very wide ranges are to some extent the result of outliers but for many categories there were large numbers of very salty products.

Compared with the 2010 data there was an increase in the mean $\mathrm{Na}$ content of four food groups (cereal and grain products, $+30 \%$; dairy and dairy alternatives, $+99 \%$; non-alcoholic beverages, $+103 \%$; sauces and spreads, $+50 \%$; all $P<0.05$ ) and a decrease in none (Table 3 ). Evaluation of median values showed significant increases in the $\mathrm{Na}$ content of six food groups and decreases in none (see online supplementary material, Supplemental Table 1).

\section{Proportion of packaged foods meeting UK Department of Health salt reduction targets}

There were 1407 products in fourteen food sub-categories for which direct comparison could be made against 2017 
Table 1 Proportion of 5686 packaged food products in 2014 meeting Food Safety and Standards Authority of India (FSSAI) guidance for nutrition labelling and proportion labelled with sodium

\begin{tabular}{|c|c|c|c|c|}
\hline & \multicolumn{2}{|c|}{ Meet FSSAI regulation } & \multicolumn{2}{|c|}{$\mathrm{Na}$ labelled } \\
\hline & $n / N$ & $\%$ & $n / N$ & $\%$ \\
\hline Bread and bakery products & $378 / 600$ & 63 & $162 / 600$ & 27 \\
\hline Biscuits & $303 / 395$ & 77 & $109 / 395$ & 28 \\
\hline Cereal and grain products & $339 / 771$ & 44 & $225 / 771$ & 29 \\
\hline Indian breakfast products & $50 / 70$ & 71 & $42 / 70$ & 60 \\
\hline Breakfast cereal & $96 / 113$ & 85 & $68 / 113$ & 60 \\
\hline Noodles & $54 / 66$ & 82 & $27 / 66$ & 41 \\
\hline Confectionery & $183 / 346$ & 53 & $91 / 346$ & 26 \\
\hline Convenience foods & $124 / 174$ & 71 & $116 / 174$ & 67 \\
\hline Ready meals & $70 / 74$ & 95 & $49 / 74$ & 66 \\
\hline Soup & $43 / 86$ & 50 & $61 / 86$ & 71 \\
\hline Dairy and dairy alternatives & $185 / 289$ & 64 & $130 / 289$ & 45 \\
\hline Processed cheese & $15 / 46$ & 33 & $41 / 46$ & 89 \\
\hline Edible oils and oil emulsions & $21 / 142$ & 15 & $8 / 142$ & 6 \\
\hline Fish and fish products & $21 / 46$ & 46 & $31 / 46$ & 67 \\
\hline Canned fish & $9 / 18$ & 50 & $16 / 18$ & 89 \\
\hline Fruit and vegetables & $244 / 1219$ & 20 & $308 / 1219$ & 25 \\
\hline Canned vegetables & $29 / 34$ & 85 & $24 / 34$ & 71 \\
\hline Pickled vegetables & $45 / 57$ & 79 & $43 / 57$ & 75 \\
\hline Herbs and spices & $516 / 543$ & 95 & $105 / 543$ & 19 \\
\hline Meat and meat products & $15 / 61$ & 25 & $12 / 61$ & 20 \\
\hline Non-alcoholic beverages & $310 / 659$ & 47 & $158 / 659$ & 24 \\
\hline Sauces and spreads & $235 / 572$ & 41 & $271 / 572$ & 47 \\
\hline Meal-based sauces & $97 / 187$ & 52 & $98 / 187$ & 52 \\
\hline Table sauces & $23 / 62$ & 37 & $33 / 62$ & 53 \\
\hline Snack foods & $292 / 504$ & 58 & $200 / 504$ & 40 \\
\hline Extruded snacks & $41 / 60$ & 68 & $9 / 60$ & 15 \\
\hline Indian snack food & $184 / 322$ & 57 & $127 / 322$ & 39 \\
\hline Sugars, honey and related products & $26 / 145$ & 18 & $35 / 145$ & 24 \\
\hline Special foods & $95 / 158$ & 60 & $74 / 158$ & 47 \\
\hline TOTAL & $2468 / 5686$ & 43 & $1812 / 5686$ & 32 \\
\hline
\end{tabular}

$\mathrm{Na}$ targets set by the UK DoH. Overall, 382 (27\%) products in these fourteen sub-categories could be confirmed as meeting the UK DoH $2017 \mathrm{Na}$ targets (Table 4). For 755 (54\%) products there were no data about $\mathrm{Na}$ content available. For the remaining 652 (46\%) products with reported $\mathrm{Na}$ content, $\mathrm{Na}$ levels were known to be above the target level for 270 products (41\%). Known compliance with the 2017 UK DoH $\mathrm{Na}$ targets ranged from $15 / 34(44 \%)$ in the canned vegetables sub-category to $2 / 56(4 \%)$ in the savoury biscuits category.

\section{Discussion}

The data collected in the current survey of 5686 products from Indian supermarkets raise concerns about the quality of nutrition labelling as well as the levels of $\mathrm{Na}$ in packaged food items for sale in India. While it appears that labelling of required nutrients for packaged food has increased in several major food groups over recent years, the proportion of foods with labelling meeting local regulations is still less than half of what is available for sale. Likewise, only a third of all packaged food items had $\mathrm{Na}$ values reported on the label and as such it is very difficult to be sure about the $\mathrm{Na}$ levels of the majority of Indian packaged foods. Furthermore, benchmarking the available data against the UK Na targets shows that many products contain unnecessarily high levels of $\mathrm{Na}$.

While the FSSAI labelling regulations meet some of the requirements of the international body governing food labelling, Codex Alimentarius, global guidelines set by Codex suggest the additional reporting of saturated fat and $\mathrm{Na}^{(19)}$. For consumers to make fully informed choices about the healthiness of products they want to purchase, food will need to display all relevant nutrition information, and FSSAI would do well to adopt the Codex guidance on $\mathrm{Na}$ and saturated fat labelling to achieve this.

Data for the current survey were collected after the 2011 introduction of the FSSAI labelling requirements. Comparison made against the 2010 data collected immediately prior allows for a direct assessment of the initial impact of the regulation. The robustness of that comparison is somewhat reduced by the different survey methodologies used and the magnitude of the difference between the proportions recorded as compliant at each time point may be biased as a consequence. However, the large proportion of foods with non-compliant packaging in the most recent survey leaves little doubt about the persisting problems with achieving even basic nutrition labelling of foods in India. The low levels of Na reporting are unsurprising given the absence of any regulatory requirement 
Table 2 Comparison of the proportion of packaged food products meeting Food Safety and Standards Authority of India (FSSAI) guidance for nutrition labelling and the proportion labelled with sodium between 2010 and 2014

\begin{tabular}{|c|c|c|c|c|c|c|}
\hline & \multicolumn{3}{|c|}{ Meet FSSAI regulation (\%) } & \multicolumn{3}{|c|}{ Na labelled (\%) } \\
\hline & 2010 & 2014 & $P$ value & 2010 & 2014 & $P$ value \\
\hline Bread and bakery products & 67 & 63 & 0.12 & 38 & 27 & $<0.001$ \\
\hline Biscuits & 72 & 77 & $0 \cdot 17$ & 42 & 28 & $<0.001$ \\
\hline Cereal and grain products & 44 & 44 & 0.95 & 45 & 29 & $<0.001$ \\
\hline Indian breakfast products & 29 & 71 & $<0.001$ & 74 & 60 & 0.04 \\
\hline Breakfast cereal & 68 & 85 & 0.002 & 71 & 60 & 0.01 \\
\hline Noodles & 70 & 82 & 0.13 & 45 & 41 & 0.63 \\
\hline Confectionery & 45 & 53 & 0.03 & 31 & 26 & 0.13 \\
\hline Convenience foods & 59 & 71 & 0.03 & 72 & 67 & 0.31 \\
\hline Ready meals & 51 & 95 & $<0.001$ & 70 & 66 & 0.59 \\
\hline Soup & 71 & 50 & 0.01 & 75 & 71 & 0.61 \\
\hline Dairy and dairy alternatives & 44 & 64 & $<0.001$ & 46 & 45 & 0.90 \\
\hline Processed cheese & 0 & 33 & $<0.001$ & 53 & 89 & $<0.001$ \\
\hline Edible oils and oil emulsions & 0 & 15 & $<0.001$ & 7 & 6 & 0.68 \\
\hline Fish and fish products & 13 & 46 & $<0.001$ & 58 & 67 & 0.34 \\
\hline Canned fish & 22 & 50 & 0.04 & 66 & 89 & $0 \cdot 10$ \\
\hline Fruit and vegetables & 12 & 20 & $<0.001$ & 32 & 25 & $<0.001$ \\
\hline Canned vegetables & 41 & 85 & $<0.001$ & 52 & 71 & 0.12 \\
\hline Pickled vegetables & 43 & 79 & 0.001 & 54 & 75 & 0.04 \\
\hline Herbs and spices & 25 & 95 & $<0.001$ & 28 & 19 & $<0.001$ \\
\hline Meat and meat products & 16 & 25 & 0.23 & 41 & 20 & 0.01 \\
\hline Non-alcoholic beverages & 4 & 47 & $<0.001$ & 38 & 24 & $<0.001$ \\
\hline Sauces and spreads & 42 & 41 & 0.75 & 49 & 47 & 0.73 \\
\hline Meal-based sauces & 48 & 52 & 0.39 & 44 & 52 & 0.22 \\
\hline Table sauces & 33 & 37 & 0.65 & 67 & 53 & 0.11 \\
\hline Snack foods & 34 & 58 & $<0.001$ & 35 & 40 & 0.16 \\
\hline Extruded snacks & 90 & 68 & 0.05 & 19 & 15 & 0.66 \\
\hline Indian snack food & 27 & 57 & 0.65 & 29 & 39 & 0.01 \\
\hline Sugars, honey and related products & 11 & 18 & 0.20 & 16 & 17 & 0.78 \\
\hline Special foods & 39 & 60 & 0.001 & 64 & 47 & 0.01 \\
\hline TOTAL & 34 & 43 & $<0.001$ & 38 & 32 & $<0.001$ \\
\hline
\end{tabular}

†Unpaired $t$ test comparing 2010 and 2014 data.

for $\mathrm{Na}$ on the nutrition label and this needs to be addressed urgently. Not only does lack of $\mathrm{Na}$ data make it impossible for consumers to quantify or control the amount of $\mathrm{Na}$ they are consuming, the absence of labelled $\mathrm{Na}$ data will also inhibit efforts to reduce $\mathrm{Na}$ levels in the food supply because it will not be possible for agencies to systematically identify and target the problem areas ${ }^{(20,21)}$.

The benchmarking we did against the UK DoH Na targets for 2017 showed both very high Na levels in some Indian products as well as marked within-category variability in the Na levels of products that were otherwise quite similar. The presence of products with very high Na levels is unsurprising since there has been no systematic national action to reduce $\mathrm{Na}$ levels in foods, nor the $\mathrm{Na}$ intake of the Indian population more broadly. The wide range of $\mathrm{Na}$ content levels within food categories shows that lower-Na formulations are both technically feasible and commercially viable for many food types. The setting of categoryspecific Na targets and the reformulation of foods high in $\mathrm{Na}$ down to the maximum acceptable level for that category is an easy early win for a national salt reduction effort and could be made a priority for India. Further, this type of reformulation programme could be commenced with minimum investment and in a short time frame by adopting or adapting targets already set in other jurisdictions $^{(12,20)}$. Some national and multinational food manufacturers operating within India likely already have internal standards relating to labelling requirements and some may also have set $\mathrm{Na}$ reduction targets. Another fairly easy first step towards improving labelling and controlling the Na levels in foods marketed in India would be to summarise these initiatives and quantify the completeness of implementation. Periodic monitoring using repeat surveys with a standardised methodology will be important and, once again, would be greatly facilitated by concurrently mandating more complete reporting of all important nutrients on packaged foods.

Strengths of the present study are its large size, the inclusion of all products for sale in the stores surveyed, the comparison against the prior 2010 survey and the benchmarking done against the UK DoH $2017 \mathrm{Na}$ targets. The restriction of the survey to Hyderabad and New Delhi is a limitation because it is unlikely that the products included in the survey are truly representative of all products available for sale in India. That said, the manufacturers with included products are the major suppliers nationally and it is likely that the products included in the study would be available in many other parts of the country. 
Table 3 Comparison of the mean salt content of food products for which sodium was labelled between 2010 and 2014

\begin{tabular}{|c|c|c|c|c|c|c|}
\hline & \multicolumn{6}{|c|}{ Na content $(\mathrm{mg} / 100 \mathrm{~g})$} \\
\hline & 2010 Mean & Range & 2014 Mean & Range & Difference & $95 \% \mathrm{Cl}$ \\
\hline Bread and bakery products & 338 & $1-11420$ & 445 & $2-4000$ & +108 & $-54,+270$ \\
\hline Biscuits & 276 & $1-1770$ & 262 & $6-764$ & -14 & $-75,+47$ \\
\hline Cereal and grain products & 327 & $0-7000$ & 477 & $0-7250$ & $+149^{\star}$ & $+22,+277$ \\
\hline Indian breakfast products & 857 & $1-2100$ & 847 & $0-2110$ & -10 & $-311,+291$ \\
\hline Breakfast cereal & 355 & $0-7000$ & 265 & $2-2100$ & -90 & $-302,+121$ \\
\hline Noodles & 517 & $1-2142$ & 670 & $21-7250$ & +150 & $-202,+503$ \\
\hline Confectionery & 249 & $0-2200$ & 98 & $0-347$ & -151 & $-513,+212$ \\
\hline Convenience foods & 1881 & $1-9970$ & 1344 & $0-5378$ & -537 & $-1092,+18$ \\
\hline Ready meals & 1148 & 0-9970 & 479 & $0-1400$ & $-669^{*}$ & $-1272,-66$ \\
\hline Soup & 2911 & $0-7520$ & 2117 & $180-5378$ & -794 & $-1670,+82$ \\
\hline Dairy and dairy alternatives & 257 & $0-1521$ & 513 & 0-2000 & $+256^{*}$ & $+133,+380$ \\
\hline Processed cheese & 1073 & $12-1521$ & 1074 & $840-1730$ & +1 & $-220,+222$ \\
\hline Edible oils and oil emulsions & 202 & $0-1048$ & 217 & $0-1048$ & +15 & $-182,+213$ \\
\hline Fish and fish products & 348 & $50-600$ & 451 & $38-887$ & +104 & $-11,+218$ \\
\hline Canned fish & 395 & $50-600$ & 457 & $48-870$ & +63 & $-64,+189$ \\
\hline Fruit and vegetables & 555 & $0-17690$ & 769 & $0-8000$ & +212 & $-22,448$ \\
\hline Canned vegetables & 229 & $37-630$ & 84 & $0-384$ & $-145^{\star}$ & $-232,-58$ \\
\hline Pickled vegetables & 1397 & $10-3790$ & 1759 & $1-8000$ & +362 & $-475,+1200$ \\
\hline Herbs and spices & 1026 & $0-17690$ & 1468 & $0-8000$ & +442 & $-130,+1014$ \\
\hline Meat and meat products & 373 & $0-2381$ & 414 & $2-1000$ & +40 & $-274,+355$ \\
\hline Non-alcoholic beverages & 59 & $0-1210$ & 119 & $0-957$ & $+61^{*}$ & $+23,+99$ \\
\hline Sauces and spreads & 1473 & $0-11200$ & 2217 & $0-21218$ & $+744^{*}$ & $+268,+1221$ \\
\hline Meal-based sauces & 1525 & $0-11200$ & 3240 & $179-21218$ & $+1714^{\star}$ & $+638,+2790$ \\
\hline Table sauces & 771 & $10-7720$ & 1020 & $1-2400$ & +249 & $-190,+687$ \\
\hline Snack foods & 573 & $0-2500$ & 666 & $0-2300$ & +93 & $-13,+199$ \\
\hline Extruded snacks & 359 & $125-650$ & 491 & $105-1179$ & +132 & $-361,+624$ \\
\hline Indian snack food & 646 & $0-2500$ & 627 & $0-2000$ & +20 & $-167,+128$ \\
\hline Sugars, honey and related products & 321 & $0-7400$ & 44 & $0-400$ & -278 & $-777,+222$ \\
\hline Special foods & 219 & $39-565$ & 239 & $57-788$ & +20 & $-36,+76$ \\
\hline
\end{tabular}

${ }^{\star} P<0.05$.

Table 4 Comparison of sodium content in selected food categories against UK Department of Health (DoH) 2017 sodium targets

\begin{tabular}{|c|c|c|c|c|c|c|c|}
\hline & \multicolumn{2}{|c|}{ Na content } & \multicolumn{2}{|c|}{$\begin{array}{l}\text { Na content of labelled } \\
\text { foods }(\mathrm{mg} / 100 \mathrm{~g})\end{array}$} & \multirow{2}{*}{$\begin{array}{c}\text { UK DoH } 2017 \text { max. } \\
\text { Na target }(\mathrm{mg} / 100 \mathrm{~g}) \\
\text { Range }\end{array}$} & \multicolumn{2}{|c|}{$\begin{array}{l}\text { Products known to meet } \\
\text { UK DoH } 2017 \text { max. Na target }\end{array}$} \\
\hline & $n / N$ & $\%$ & Mean & Range & & $n / N$ & $\%$ \\
\hline \multicolumn{8}{|c|}{ Bread and bakery products } \\
\hline Sweet biscuits & $105 / 339$ & 31 & 258 & $6-701$ & 380 & $84 / 339$ & 25 \\
\hline Savoury biscuits & $4 / 56$ & 7 & 515 & $300-764$ & 700 & $2 / 56$ & 4 \\
\hline \multicolumn{8}{|c|}{ Cereal and grain products } \\
\hline Breakfast cereal & $68 / 113$ & 60 & 265 & $0-2110$ & 400 & $49 / 113$ & 43 \\
\hline Noodles & $29 / 66$ & 44 & 670 & $21-7250$ & 350 & $11 / 66$ & 17 \\
\hline Pasta & $43 / 74$ & 58 & 52 & $0-1000$ & 350 & $42 / 74$ & 57 \\
\hline \multicolumn{8}{|l|}{ Convenience foods } \\
\hline Ready meals & $49 / 74$ & 66 & 479 & $0-1400$ & 380 & $15 / 74$ & 20 \\
\hline Soup & $61 / 86$ & 71 & 2117 & $180-5378$ & 250 & $20 / 86$ & 23 \\
\hline \multicolumn{8}{|c|}{ Dairy and dairy alternatives } \\
\hline Processed cheese & $41 / 46$ & 89 & 1074 & $840-1730$ & 800 & $9 / 46$ & 20 \\
\hline \multicolumn{8}{|l|}{ Fish and fish products } \\
\hline Canned fish & $16 / 18$ & 89 & 457 & $48-870$ & 360 & $5 / 18$ & 28 \\
\hline \multicolumn{8}{|l|}{ Fruit and vegetables } \\
\hline Canned vegetables & $24 / 34$ & 71 & 84 & $0-384$ & 50 & $15 / 34$ & 44 \\
\hline Pickled vegetables & $43 / 57$ & 75 & 1759 & $1-8000$ & 1500 & $21 / 57$ & 37 \\
\hline \multicolumn{8}{|l|}{ Sauces and spreads } \\
\hline Table sauce & $33 / 62$ & 53 & 1020 & $1-2400$ & 680 & $6 / 62$ & 10 \\
\hline \multicolumn{8}{|l|}{ Snack foods } \\
\hline Extruded snacks & $9 / 60$ & 15 & 491 & $105-1179$ & 800 & $8 / 60$ & 13 \\
\hline Indian snack foods & $127 / 322$ & 38 & 627 & 0-2000 & 1000 & 95/322 & 29 \\
\hline TOTAL & $652 / 1407$ & 46 & & & & $382 / 1407$ & 27 \\
\hline
\end{tabular}

The descriptions of mean $\mathrm{Na}$ values in Indian packaged foods need to be treated with caution because of the incomplete nature of the data, but there is certainly no evidence of any systematic reduction in the mean $\mathrm{Na}$ content of Indian packaged foods over recent years. The observation of a comparable pattern of change in the 
analyses of median values is confirmatory of the main findings. Quality control, both by the data management centre at the time of data capture and through the application of extensive data checks during the analysis stage, has provided for a clean and coherent data set. Direct food testing by way of chemical analysis would have provided further reassurance of the validity of the $\mathrm{Na}$ values reported but this is an expensive process and was beyond the scope of this project. Additionally, data on the market share for each product would have allowed a more comprehensive, weighted analysis to determine the likely contribution of each food group and food category to total $\mathrm{Na}$ intake in the population. Finally, it is likely that some of the products for which data were collected between 2012 and 2014 are no longer on the shelves of Indian supermarkets but it is also unlikely that the product mix and its average composition are substantially different from that reported here.

Chronic diseases are substantially attributed to poor diet and are the leading cause of death and disability worldwide $^{(1)}$. The present study's findings are fundamental to understanding the impact of adverse nutrients in the Indian food supply and will underpin the development of strategies to address them.

\section{Conclusion}

The Government of India has identified food labelling as an important population-based initiative for the prevention of diet-related disease ${ }^{(11)}$, but while a regulation is now in place it is clear that additional enforcement will be required to achieve full compliance. Likewise, the absence of voluntary labelling of $\mathrm{Na}$ indicates that the regulation will need updating if it is to have the full health impact sought. Given the very large burden of disease attributed to excess $\mathrm{Na}$ consumption in India ${ }^{(3)}$, the establishment of $\mathrm{Na}$ targets for key product categories would be a reasonable early step. A broad-based national salt reduction programme in India would appear to have enormous potential to avert very large numbers of premature heart attacks, strokes and other blood pressure-related diseases $^{(20)}$.

\section{Acknowledgements}

Financial support: This work was supported by a funding award made by the Global Alliance for Chronic Disease through the National Health and Medical Research Council of Australia (NHMRC) (grant number APP1040179). C.J. is supported by an NHMRC postgraduate scholarship (grant number APP1074678). J.H.Y.W. is supported by an NHMRC/National Heart Foundation Career Development Fellowship (grant number APP1082924). B.N. is supported by an NHMRC Principal Research Fellowship (grant number APP1106947). He also holds an NHMRC Program Grant (grant number APP1052555). P.K.M. is an Intermediate Career Fellow of the WT/DBT India Alliance. R.S. is supported by a Wellcome Trust Capacity Strengthening Strategic Award Extension phase to the Public Health Foundation of India and a consortium of UK universities (grant number WT084754/Z/08/A). E.D. is supported by an NHMRC Early Career Fellowship. The funders had no role in the design, analysis or writing of this article. Conflict of interest: The authors have no conflict of interest to declare. Author contributions: C.J. conducted and analysed the research and wrote the first draft of this paper with primary responsibility for the final content. B.N. and D.P. designed the research and B.N. edited the manuscript for important content. All authors reviewed and provided written comments upon subsequent iteration. Ethics of buman subject participation: Not applicable.

\section{Supplementary material}

To view supplementary material for this article, please visit https://doi.org/10.1017/S1368980017001987

\section{References}

1. Lim S, Vos T, Flaxman A et al. (2013) A comparative risk assessment of burden of disease and injury attributable to 67 risk factors and risk factor clusters in 21 regions, 1990-2010: a systematic analysis for the Global Burden of Disease Study 2010. Lancet 380, 2224-2260.

2. Gupta R (2004) Trends in hypertension epidemiology in India. J Hum Hypertens 18, 73-78.

3. Mozaffarian D, Fahimi S, Singh G et al. (2014) Global sodium consumption and death from cardiovascular causes. $N$ Engl J Med 371, 624-634.

4. World Health Organization (2013) Global action plan for the prevention and control of, noncommunicable diseases 2013-2020. https://apps.who.int/iris/bitstream/10665/94384/ 1/9789241506236_eng.pdf?ua=1 (accessed October 2016).

5. World Health Organization (2012) Guideline: Sodium Intake for Adults and Children. Geneva: WHO.

6. Misra A, Singhal N, Sivakumar B et al. (2011) Nutrition transition in India: secular trends in dietary intake and their relationship to diet-related non-communicable diseases. J Diabetes 3, 278-292.

7. National Sample Survey Organisation (2007) Nutritional Intake in India 2004-2005. http://mospi.nic.in/sites/default/files/ publication_reports/513_final.pdf (accessed October 2016).

8. Food and Agriculture Organization of the United Nations (2006) The double burden of malnutrition: case studies from six developing countries. http://www.fao.org/docrep/009/ a0442e/a0442e00.htm (accessed May 2016).

9. Johnson C, Mohan S, Rogers K et al. (2017) Mean dietary salt intake in urban and rural areas in India: a population survey of 1395 persons. J Am Heart Assoc 6, e004547.

10. Johnson C, Praveen D, Pope A et al. (2017) Mean population salt consumption in India: a systematic review. J Hypertens 35, 3-9.

11. Ministry of Health and Family Welfare, Government of India (2013) National Action Plan and Monitoring Framework for Prevention and Control of NCDs. http://www.searo.who. int/india/topics/cardiovascular_diseases/National_Action_ 
Plan_and_Monitoring_Framework_Prevention_NCDs.pdf? ua $=1$ (accessed June 2016).

12. Trieu K, Neal B, Hawkes C et al. (2015) Salt reduction initiatives around the world - a systematic review of progress towards the global target. PLoS One 10, e0130247.

13. Food Standards Agency (2009) Food Standards Agency Salt Commitments Table (2009-2010). Retailers. https://www.food. gov.uk/sites/default/files/multimedia/pdfs/saltcommitmentsmay 2010.pdf (accessed October 2016).

14. Webster J, Trieu K, Dunford E et al. (2014) Target salt 2025: a global overview of national programs to encourage the food industry to reduce salt in foods. Nutrients $\mathbf{6}$, 3274-3287.

15. Food Safety and Standards Authority of India (2011) Food Safety and Standards (Packaging and Labelling) Regulations. https://www.fssai.gov.in/dam/jcr:61b5ecf1-7a41-4185-84854a7f68f71c2b/Compendium_Packaging_Labelling_Regulations. pdf (accessed May 2016).

16. Dunford E, Guggilla R, Ratneswaran A et al. (2015) The adherence of packaged food products in Hyderabad, India with nutritional labelling guidelines. Asia Pac J Clin Nutr 24, 540-545.

17. The George Institute for Global Health (2014) Instructions for using The George Institute's Data Collection App Version 1.2. http://www.georgeinstitute.org/sites/default/files/ instructions-for-data-collector-app-for-supplement-database. pdf (accessed May 2016).

18. Dunford E, Webster J, Metzler A et al. (2012) International collaborative project to compare and monitor the nutritional composition of processed foods. Eur J Prev Cardiol 19, 1326-1332.

19. Codex Alimentarius (2011) Guidelines on Nutrition Labelling. http:/www.fao.org/docrep/005/Y2770E/y2770e06.htm (accessed May 2016).

20. He F, Brinsden H \& MacGregor G (2014) Salt reduction in the United Kingdom: a successful experiment in public health. J Hum Hypertens 28, 345-352.

21. Webster J, Dunford E, Huxley R et al. (2009) The development of a national salt reduction strategy for Australia. Asia Pac J Clin Nutr 18, 303-309. 